\title{
Comparative efficacy of manuka honey and povidone gel on healing of induced incisional wounds in rabbits
}

\author{
Nosheen Saleem ${ }^{1}$, Khurram Ashfaq ${ }^{1}$, Shahzad Akbar Khan ${ }^{2 *}$, \\ Muhammad Saqib ${ }^{1}$, Muhammad Fakhar-E-Alam Kulyar ${ }^{1}$, Memooma \\ Mehmood $^{1}$ and Anees Khalid ${ }^{3}$ \\ 1. Department of Clinical Medicine and Surgery, University of Agriculture, Faisalabad-Pakistan \\ 2. Department of Pathobiology, Faculty of Veterinary and Animal Sciences, University of the Poonch \\ Rawalakot AJK, 12350-Pakistan \\ 3. Arid Agriculture University, Rawalpindi-Pakistan \\ *Corresponding author's email: shahzadakbar@upr.edu.pk \\ Citation \\ Nosheen Saleem, Khurram Ashfaq, Shahzad Akbar Khan, Muhammad Saqib, Muhammad Fakhar-E-Alam \\ Kulyar, Memooma Mehmood and Anees Khalid. Comparative efficacy of manuka honey and povidone gel on \\ healing of induced incisional wounds in rabbits. Pure and Applied Biology. Vol. 9, Issue 1, pp1385-1395.
} http://dx.doi.org/10.19045/bspab.2020.90145

\begin{tabular}{llll}
\hline \hline Received: $29 / 10 / 2019$ & Revised: 30/12/2019 & Accepted: 07/02/2020 & Online First: 28/02/2020 \\
\hline \hline
\end{tabular}

\section{Abstract}

In human and veterinary practices wound management is still a burden either from undesirable events or surgical operation. Various traditional medications have been used for treatment of wound such as turmeric, Aloe vera gel, ancient herbs, neem leaves, alcohol and antibiotics. In wound healing process the old drug which has broad range of effects is honey. Povidone gel has been used in treatment of wounds, but also used as skin antiseptic before surgery and disinfection of inert surfaces. The objective of this research was to estimate the relative effectiveness of manuka honey as well as povidone gel on incisional wound in rabbits. A whole of 28 strong male rabbits were chosen and divide into four groups $v i z$, Treatment group 1, $2^{\text {nd }}$ treatment Group , Group T3 as well as Group T4.Incisional wound was created in rabbits by sharp blunt scissor. Group T1 was cured with manuka honey, GroupT2 was received medication of povidone gel, Group T3was cured with combination of both manuka honey plus povidone gel.Group T4 was kept as untreated. The efficacy of treatment was analyzed in terms of wound compression, repairing of wound as well as histopathological evaluation. For statistical analysis the data of pre and post treatment of wounds were tested through one way ANOVA by using SPSS software. So, it is concluded that the practice of manuka honey in mixture with equal quantity of povidone iodide for treatment of induced incisional open wounds in human as well as in animals. This combination is effective and can be used without any fear of demerits.

Keywords: Avulsions; Abrasion; Antiseptic; Povidone gel; Wound

\section{Introduction}

As a consequence of any trauma, physical, chemical as well as thermal injury breakage in the continuity of skin and soft tissues termed as wound. In animals and man cutaneous wounds are concurrence commonly all over the world. Open and closed two types of wounds classify depending upon the intensity and type of trauma as well as surgical procedure. Open wounds consist of abrasions, ballistic, lacerated, and penetrating. Surgical, avulsions, hernia and excised. Wounds also classified as clean and contaminated wound. For the management of wounds different steps involved drainage of wound, debridement of dead and dying tissues, inhibition of further wound contamination, advancement of viable bed establishment as well as selection of suitable method of 
wound closure. The purpose of any treatment to speed up wound healing process by providing the clean warm and adequate amount of blood supply. Povidone iodide is an iodine solution comprising free iodine and PVP. The bactericidal action of povidone is relative to the deliberation of free iodine. PVP has not at all antimicrobial ability on the other hand its fellow feeling for cell membranes improve the efficiency of free iodine as well as decrease the staining, as well as tissue exasperation related with free iodine. Povidone has good antimicrobial property against Grampositive plus Gram-negative bacteria, Candida plus fungi. Bacterial confrontation to iodine not been identified. PI has a residual ability of only $4-6$ hours in addition to this hence requires frequent implementation. It is put out of action by organic matter and hence sufficient debridement and irrigation is mandatory for effective antisepsis. PI grades in fibroblast plus leukocyte cytotoxicity, inhibited neutrophil migration, reduced lymphocyte blastogenesis and limited granulocyte and monocyte viability. PI can cause acute contagious dermatitis, metabolic acidosis, thyroid dysfunction, and ototoxicity. Detergents formed by merging surfactants with PI are damaging to wound tissue and potentiate infection. Other antiseptics include alcohol, sodium hypochlorite (or Dakin's solution), quaternary ammonium compounds, acetic acid, hydrogen peroxideand silver nitrate. These antiseptics do not have the broad spectrum effectiveness wide edge of sanctuary of CHD and PI [1].

In all body tissue the capability of healing by the replication of cells regeneration as well as replacement of damaged tissue by connective tissue repair [2]. Honey has ability to lower the prostaglandins level and elevates the nitric acid level due to this honey maintain its therapeutic effect and acts as a wound healer [3, 4].The healing progression plus nutritional effects on wound consequence is severe to effective organization of wound [5]. In clinical practices it has been proven that there is less exudate formation, reduced edema and minimal scar formation after the use of honey for the management of wounds [6].

\section{Materials and methods}

This experiment was conducted induced surgically full thickness cutaneous incisional wound on the thoraco- lumber region of 28 healthy male rabbits.

\section{Purchasing of experimental rabbits and grouping}

From the local market of Faisalabad a total of 28 healthy two weeks old male rabbits weighing 1000-1500gm were purchased. The animals were kept in a well-ventilated animal room under12/12 hour light and dark cycle at the Department of Clinical Medicine and Surgery, University of Agriculture, Faisalabad. Four groups of rabbits were made having 7 rabbits each. For proof of identity purpose, the rabbits were marked at the interior surface of ears according to their corresponding groups using a long-lasting black marker. All rabbits were kept up on a quite even as well as homogenous feeding and management system in animal house of Department of Clinical Medicine and Surgery (CMS) throughout pre-operative and postoperative periods. All the animal experiments were performed after proper approval of Bioethic committee of Faculty of Veterinary sciences. Each group was randomly allocated to pyodine (T1), manuka honey (T2), combination of pyodine and manuka honey (T3), and control (T4).

Formerly starting the trial, the animals were kept and acclimatized for a period of 15 days in Animals lab Facility of the Department. Lime stone was used on the floor as a disinfectant in animal house to kill microorganism, viruses as well as many endospores. Animal were fed on fresh green fodder either Barseem or lucern and carrots twice a day and the availability of fresh water was ensured the whole day as they want. During the time rabbits were examined clinically during time period of 15 days in order to decrease of the chances 
of infection. During the acclimatization period each rabbit was given dose of dewormer (ivermectin) at the dose rate of 400 micro gram/kilogram through $\mathrm{S} / \mathrm{C}$ route before one week of the surgery. Almox L.A $15 \mathrm{mg} / \mathrm{kg}$ was given to overcome pasturellosis. All these prophylactic measures were completed one week before the start of experiment.

\section{Operative site preparation}

The skin as well as hair sacs are the medium for bacterial growth. The skin and follicles of hair cannot be sterilized completely. Wounds infection is mainly caused by the bacteria infestation in animals which is present on the surface of skin Bacteria on the skin surface. To minimize getting the chances of infection during the creation of surgical wounds the surface of skin is scrubbed with antiseptic solution, also by removal of hair .Some key points during this time must kept in mind i.e. removal of hair from surgical site removed carefully with minimal damaged to tissue of the skin, which imparts in bacterial infection and delayed wound healing process. So all key points must kept in mind during clipping of hairs.

Hairs are clipped closely within the surgical field is necessary in surgery [2]. So, electric clipper was recommended than the conventional razor. General razor cause skin abrasions and disturbs the outer most layer of skin, which is the first track of body protection against bacterial infection. A common guideline was follow in every case during the clipping of hair on the thoracic lumber surgical site. The area which was clipped cleaned with antiseptic scrub. After Cleaning with scrub the area was then washed with soap as well as with water, thorough cleansing.

\section{Pre-medication and Anesthesia}

Before the administration of general anesthesia the rabbits of all groups were injected premedication of atropine sulphate $\mathrm{s} / \mathrm{c}$ before the surgical procedure about half an hour to overcome any complication at the dose rate of $0.035 \mathrm{mg} / \mathrm{kg}$. The general anesthesia was prepared by using a mixture of xylazine as well as ketamine $(5 \mathrm{mg} / \mathrm{kg}$, $35 \mathrm{mg} / \mathrm{kg}$ ) [7]. The administration of anesthesia is through intramuscular route the animals were anesthetized.

\section{Recumbency of rabbit and draping of surgical site}

The rabbits were lying down in sternal recumbency. The operative site was cleaned and disinfected with iodine, through alcohol swabbing prior to surgical intervention. To prevent the surrounding skin environment from contamination an effective system of draping was used. Draping system is a mandatory barrier from contamination of infection. Penetration of bacteria is more in wet drapes cloth as compared to dry drapes. The dry drape is barrier for contaminants, so we were used wet dry drape in our research trail. All these important key points was kept in mind before the starting the procedure of experiment.

\section{Surgical wounds infliction and identification marks}

The area of wounds were marked for identification with permanent green marker. The wound area measurement was taken with the help of vernier calipers. Complete thickness skin wounds of $4 \mathrm{~cm}^{2}$ were generated on thoraco- lumber region of rabbit. The wounds were created by using sharp blunt scissor. The instruments that were used in wounding, sterile in autoclave before using. An antiseptic solution was used to disinfectant the table and all the instrument prior to surgery. Total 28 rabbits were used in this experimental study. Rabbits were like wise allocated into four groups. A total of 2 wounds were generated on lateral side of each rabbit. Full thickness skin wound was created at right side and other wound was created at left side. By undermining the area of wound site the pieces of skin was removed with the help of scissor.

\section{Treatment protocols}

A total 28 rabbits were used in this experiment. Rabbits were arbitrarily divided into 4 groups on the basis of treatment applied. In each group 7 rabbits 
were kept. Two wounds were created one at the right side whereas the other at the left side of each rabbit, in each treatment groups. The treatment groups were named as group A, group B, group C, group D.

First Group = wounds be cured along $\mathrm{MH}$ (Manuka honey)

Group second $\mathrm{B}=$ wounds be cured with PI (Povidone iodide gel)

Group $\mathrm{C}$ third= wounds be treated with $\mathrm{MH}$ \& PI

Group fourth $\mathrm{D}=$ wounds were untreated

The topical application of MH in group A was started from the next day of creation of wound. group B rabbits were treated with povidone iodide gel alone. The combination of manuka honey and povidone iodide gel treatment was applied in group $\mathrm{C}$ animals. No treatment was applied in a group D which was kept as control group.

The wounds were kept open, after the application of medication. The treatments application were two time in a day,for the completion of complete healing process. The application of treatment continued until all the wounds were not completely healed. The rabbits were regularly observed, after the implication of treatment. Rabbits were housed in separate cages, so the licking risks of other rabbits will prevent. General body condition of all rabbits were checked on the daily basis, for any infection in wounds or any other non-specific abnormalities.

\section{Evaluation criteria}

To determine the comparative efficiency of Manuka honey alone in incisional open wound healing, to check the effect of povidone iodide gel in healing of wounds. To estimate the combine efficiency of manuka honey and povidone iodide gel in wounding of rabbits.

\section{Gross estimation of wound}

The wound of each rabbit was estimated every other day $(3,5,7,11,13,15)$ for 15 days using wetness/ dryness, color, granulation tissues as well as wounds edge edema as healing parameters. The wound of each rabbit was assessed every other day (i.e., day $3,5,7,11,13,15)$ for 15 days using wetness/dryness, color, granulation tissues and wounds edge oedema as healing parameters. Granulation tissue was categorized as outrageous, modest, or low (0). Size of wound ( $\mathrm{mm}$ ) was measured by taking the diameter of wound with the help of vernier caliper (Globetronics \& Co. ltd, Germany).

\section{Wound contraction rate}

Wound reduction was expressed as reduction in original percentage of wound size. Wounds magnitudes was carried out with the help of vernier caliper 34 on day 0 , $3,7,14$ and will be compared with the area of respective wound on day zero. The percent contraction was then calculated using the following formula.

$\%$ wound closure $=(\mathrm{A} 0-\mathrm{A} 1 / \mathrm{A} 0) \times 100$

$\mathrm{A} 0=$ Area of wound at 0 day

A1 $=$ Area of wound at 3,7 , or 14 day of post-treatment

\section{Healing time}

The time between wound formation and the day that each wound creation and the day that each wound healed. Reepithelialization of wound edges tissue and regeneration of blood vessels in healing process. It was determined by taking observation from the first day of wound until the scar had shut off [2].

\section{Histopathological studies}

For histopathological analysis the full thickness skin samples, were collected from each treatment rabbits groups on $14^{\text {th }}$ day of healing. The skin samples was preserved in a solution (neutral buffered formalin) and 70-100\% ethanol and then cleared in xylene and paraffin was used for embedding. Thick paraffin solution of 5 micron was formed. Hematoxylin and eosin dyes were used for staining and then seen with the help of microscope. After the fixation, clearing, impregnation, embedding, sectioning as well as slide staining processes. For collagen fiber deposition as well for the arrangement of fibers, skin layer thickness, and proliferation of fibroblast and angiogenesis of healed tissues were analyzed through histopathology. 


\section{Statistical Analysis}

The data was tested by ANOVA while means was compared by Tukey test at $p \leq$ 0.05 using SPSS version 22 [8].

\section{Results}

The current research was schemed as well as directed to determine the effectiveness of manuka honey singly and accompanied by povidone iodide and PI alone in the management of surgically created complete thickness wounds in rabbits. This research trail was done on $4 \mathrm{~mm}^{2}$ skin, full thickness wounds in 28 rabbits. Rabbits were allocated arbitrary into four groups 7 rabbits in each group. All general physiological norms such as normal body temperature, pulse rate, heart beat as respiration rate were taken frequently. All the parameters were found within normal criteria. None of rabbits were showed sign of off feed, however sensational increase consumption of water was noticed in all rabbits, this change may co-related with external changes of environmental weather, even though the housing area temperature maintained in the limits of comfort zone.

\section{Healing time}

The time period between the creation of wound and complete re-epithelialization as well as regeneration of wound boundaries is called healing time. The nethermost mean wound healing time $(9.16 \pm 0.57)$ were noticed in the wounds counted in Manuka honey and Povidone iodide (Group C, Table 1), the rabbits that were cured alone manuka honey (Group A, Fig. 1) mean healing time was $11.57 \pm 1.40$, the mean healing time of wounds in povidone iodide group (B) (Fig. $2 \& 3$ ) was $10.91 \pm 1.70$ and the slowest mean healing time was $14.43 \pm$ 1.27 in group (D) (Table 2). The difference in time of healing of wounds between group $\mathrm{C}$ as well as $\mathrm{B}$ was comparatively less significant $p \leq 0.05$. The healing time of group manuka honey as well as pyodine (Fig. 4 \& 5) was not too much different but in comparison with combination group there was significant differences among group A plus B in relation to the group C. Control group (Fig. $6 \&$ 7) has showed delay healing as compared to other groups so it was decided there is significant relation of control group as compared to other group.

Table 1. Total healing time of different treatments in days

\begin{tabular}{|c|c|}
\hline Treatments & Mean \pm SD \\
\hline Manuka Group & $11.57 \pm 1.40^{\mathrm{a}}$ \\
\hline Pyodine Group & $10.91 \pm 1.70^{\mathrm{a}}$ \\
\hline Manuka + Pyodine Group & $9.16 \pm 0.57^{\mathrm{ab}}$ \\
\hline Controlled Group & $14.43 \pm 1.27^{\mathrm{c}}$ \\
\hline
\end{tabular}

Different superscripts with in column shows the significant relation $p \leq 0.05$

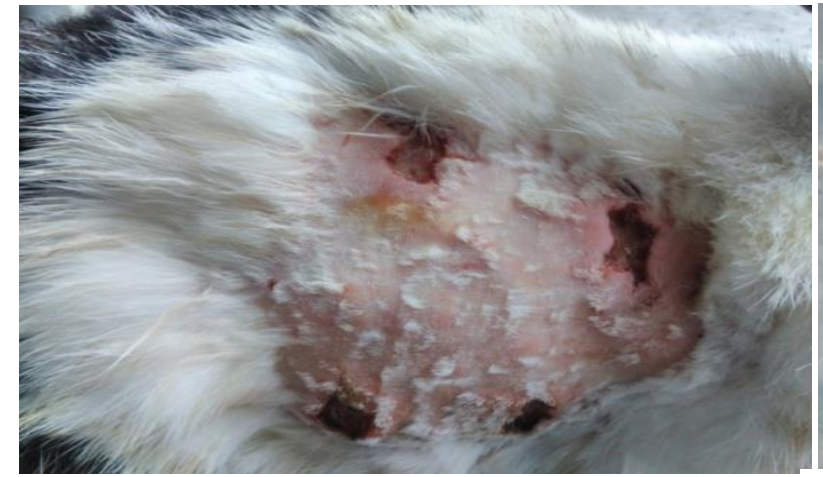

Figure 1. Application of Manuka honey on the wounds of group $A$

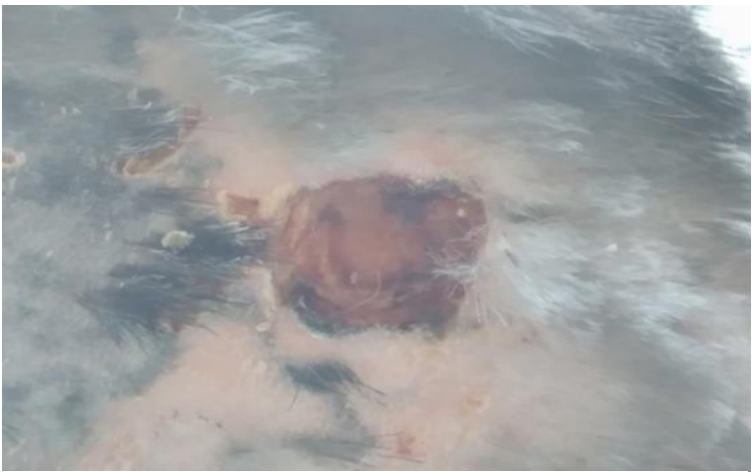

Figure 2. Wound treated with Povidone iodide 


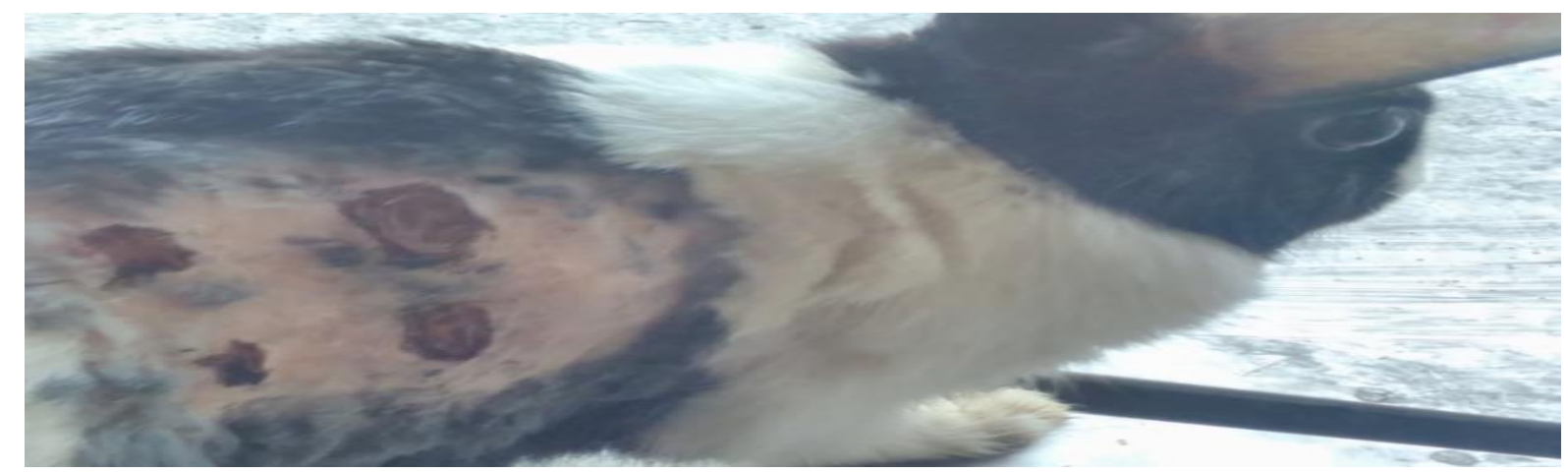

Figure 3. Wound healing in Povidone iodide group

Table 2.Wound healing according to days

\begin{tabular}{|c|c|c|c|c|c|}
\hline Treatments & Day 3 & Day 5 & Day 7 & Day 9 & Day 11 \\
\hline Manuka Group & $8.28 \pm 0.27^{\mathrm{a}}$ & $5.89 \pm 0.27^{\mathrm{a}}$ & $3.27 \pm 0.71^{\mathrm{a}}$ & $1.43 \pm 0.30^{\mathrm{a}}$ & $1.27 \pm 0.4^{\mathrm{a}}$ \\
\hline Pyodine Group & $8.21 \pm 0.42^{\mathrm{a}}$ & $5.62 \pm 0.43^{\mathrm{a}}$ & $2.76 \pm 0.53^{\mathrm{a}}$ & $0.30 \pm 0.99^{\mathrm{a}}$ & $0.12 \pm 0.02^{\mathrm{a}}$ \\
\hline $\begin{array}{c}\text { Pyodine+Manu } \\
\text { ka Group }\end{array}$ & $8.47 \pm 0.31^{\mathrm{a}}$ & $5.57 \pm 0.49^{\mathrm{a}}$ & $2.29 \pm 0.70^{\mathrm{b}}$ & $0.56 \pm 0.14^{\mathrm{b}}$ & $0.38 \pm 0.12^{\mathrm{b}}$ \\
\hline Controlled & $8.31 \pm 0.30^{\mathrm{a}}$ & $6.5 \pm 0.93^{\mathrm{a}}$ & $4.29 \pm 0.27^{\mathrm{a}}$ & $2.81 \pm 0.38^{\mathrm{a}}$ & $1.27 \pm 0.24^{\mathrm{a}}$ \\
\hline
\end{tabular}

Different superscripts with in columns show the significant difference $(p \leq 0.05)$

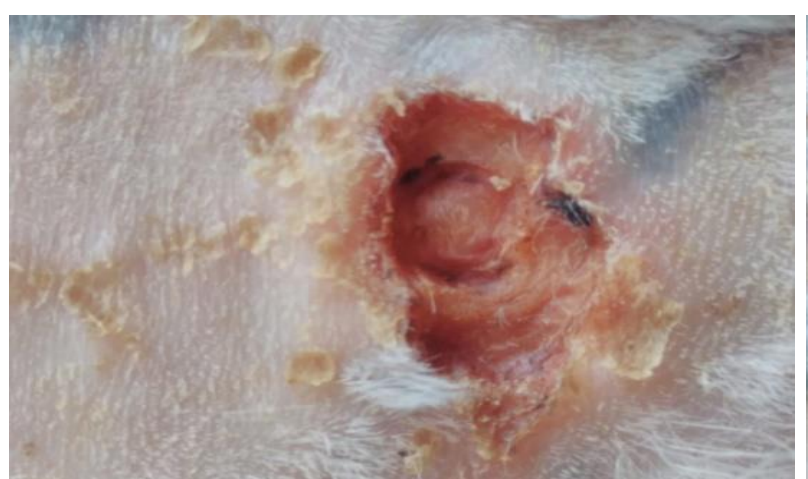

Figure 4. Wound treated with Manuka honey and Povidone Iodide

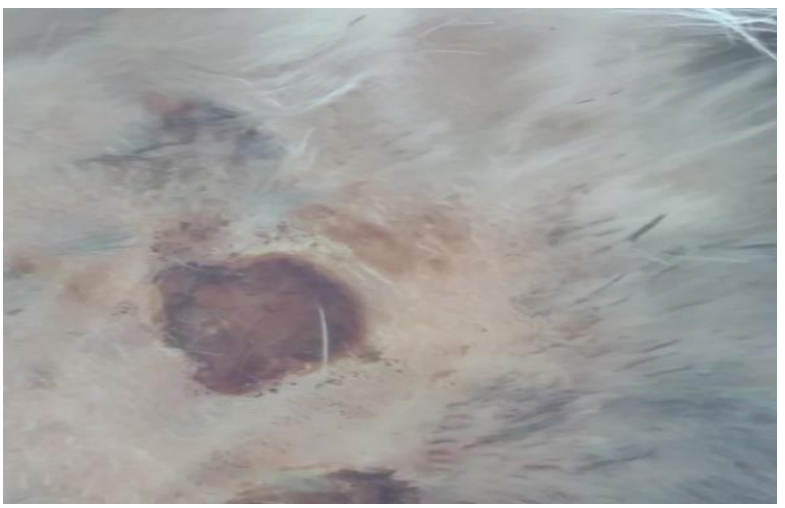

Figure 6. Control group wound

Contraction states that the movement of ends of wounds to it epicenter to close it. Subsequent initial extension all through

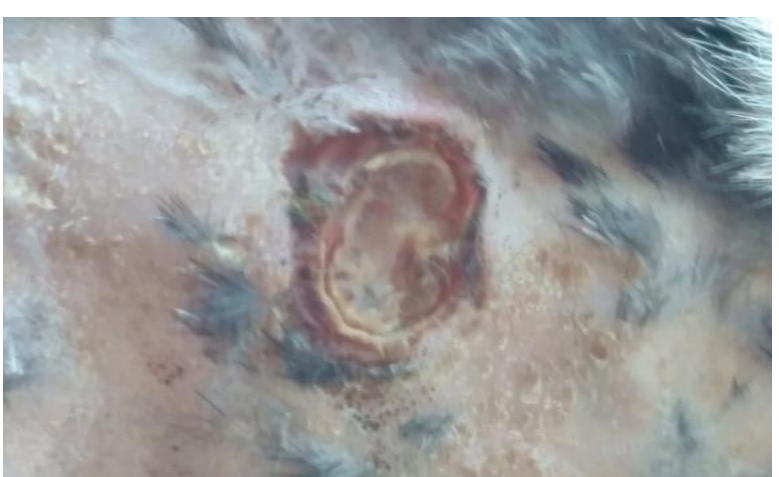

Figure 5. Wound healing in Manuka honey and povidone iodide gel group

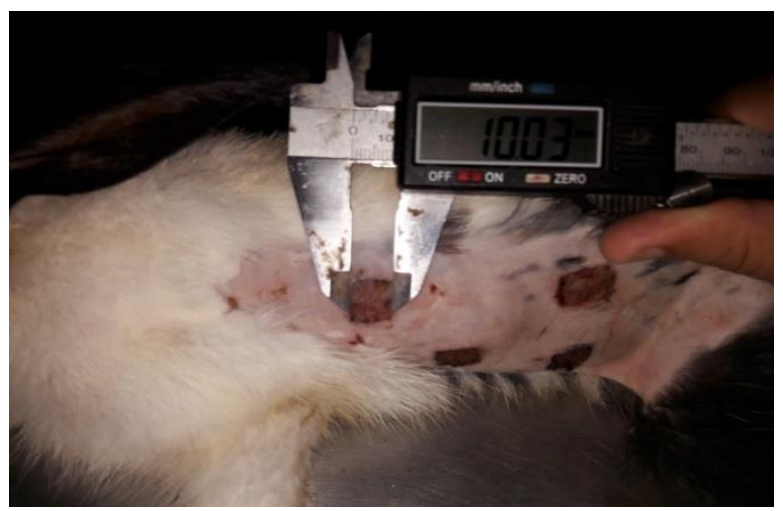

Figure 7. Wound size at day 0 in control group contraction rate

first two to three days, wholly wounds in progress constricting and this rate be measured as percent decrease ( Fig. 8) in the 
wound size from day two ahead until boundaries become united.

At day (Fig. 9) 3 and 5 the all treatment group was showed that there was no significant difference among all the groups. At day 7 contraction rate was higher in combination group as compared to other groups. Group A (Fig. 10) Manuka honey treated rabbits contraction diminished by day 11 while contraction percentage terminated on day 10 in a group B (Fig. 11) (Povidone iodide), where as in group $\mathrm{C}$ (Fig. 12) (mixture of MH \& PI) contraction completed in 9 days and in the control group D the contraction was completed in 14 days. The wound contraction rate in all groups was same at day 3. Hence the contraction was significantly almost same in all treatment groups at $3^{\text {rd }}$ day. The contraction rate was higher in treatment group in relation to control group day 5. At 7 day wound contraction rate in group B plus $\mathrm{C}$ was significantly higher in relation to group A as well as D. At $9^{\text {th }}$ day group treated with $\mathrm{MH}$ and PI show highest contraction rate as compared to other treatment groups.AT $11^{\text {th }}$ day wound contraction was completed in group $\mathrm{C}$, whereas in group $\mathrm{B}$ the contraction rate was slightly higher than group A (Table 3 ). $\mathrm{p} \leq$ 0.05 .
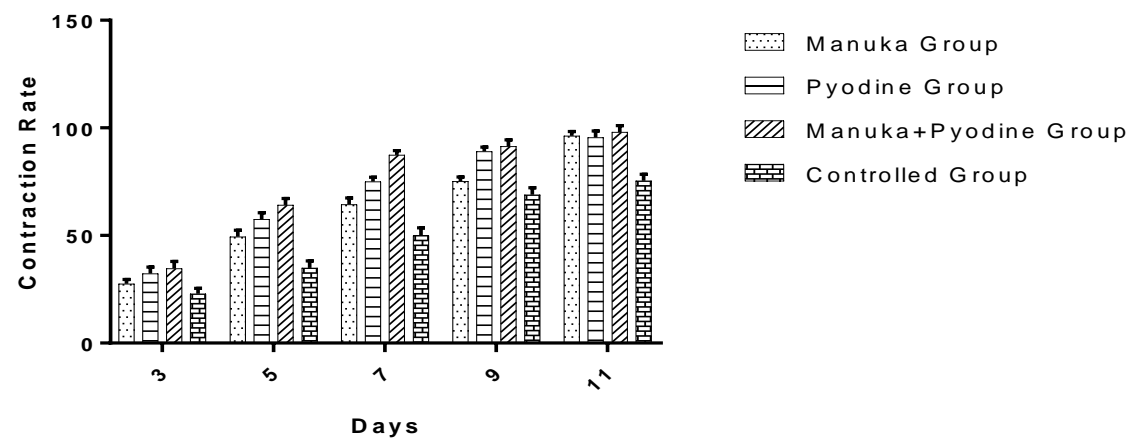

Figure 8. Wound contraction rate percentage according to days
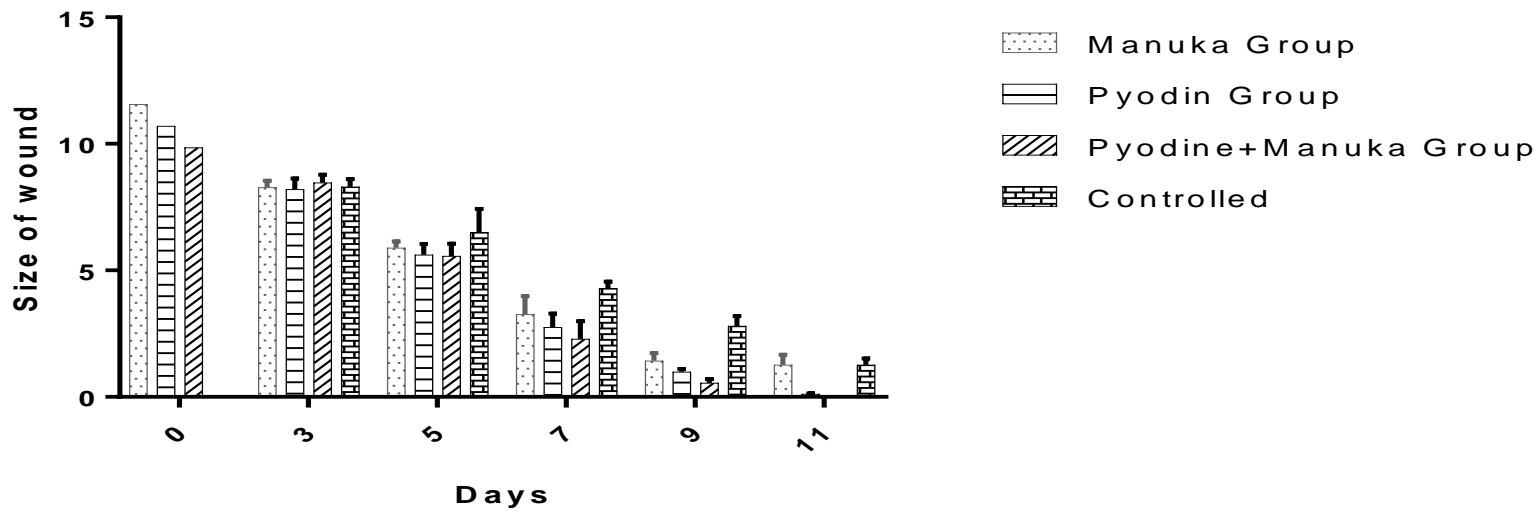

Figure 9. Wound healing according to days 


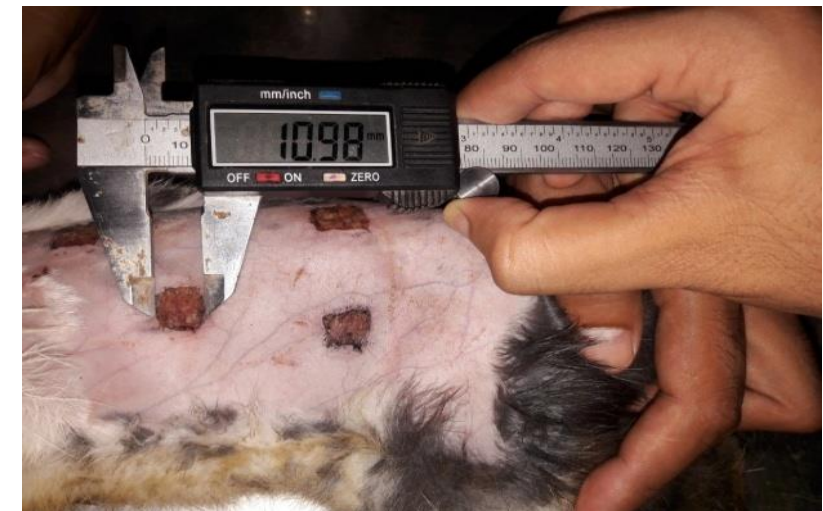

Figure 10. Wound size at 0 day in group A

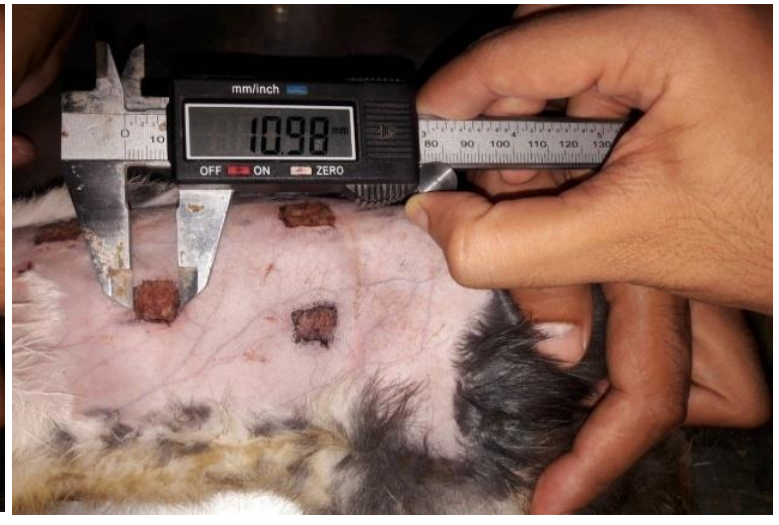

Figure 11. Wound size at 0 day in group B

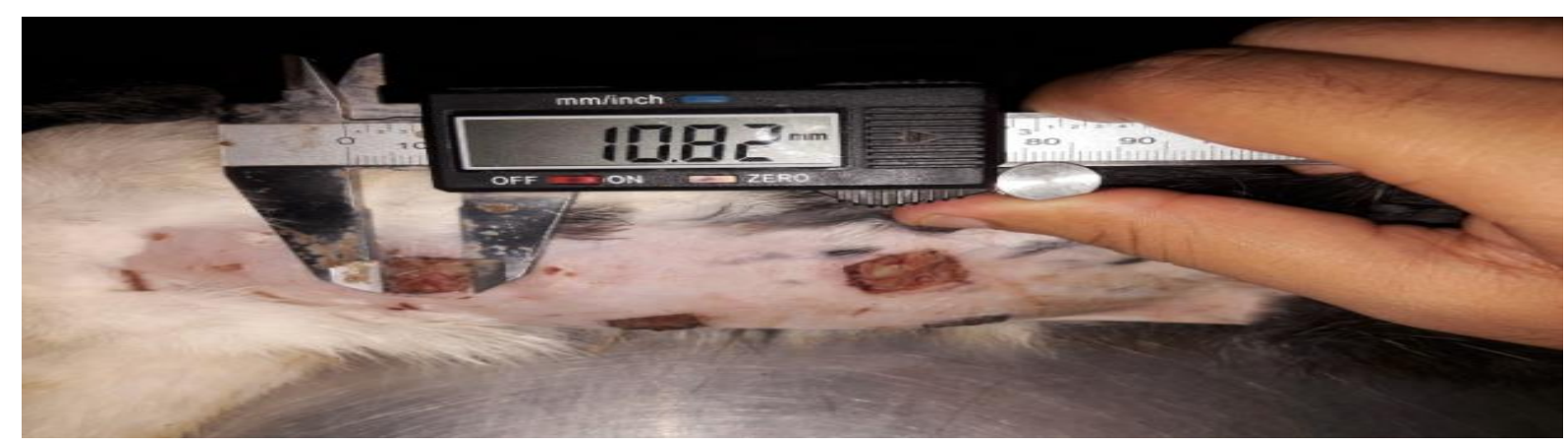

Figure 12. Wound contraction at day 0 in group $\mathrm{C}$

Table 3. Contraction Percentage according to days of different treatments

\begin{tabular}{|c|c|c|c|c|}
\hline Day & Manuka Group & Pyodine Group & $\begin{array}{c}\text { Pyodine+Manuka } \\
\text { Group }\end{array}$ & $\begin{array}{c}\text { Controlled } \\
\text { Group }\end{array}$ \\
\hline Days & Manuka Group & Povidone Group & $\begin{array}{c}\text { Povidone + Manuka } \\
\text { Group }\end{array}$ & Control Group \\
\hline 3 & 27.57 & 32.29 & 34.69 & 22.98 \\
\hline 5 & 49.38 & 57.57 & 64.18 & 34.91 \\
\hline 7 & 64.47 & 75.04 & 87.48 & 50.1 \\
\hline 9 & 75.19 & 89.02 & 91.46 & 68.99 \\
\hline 11 & 96.32 & 95.56 & 98.00 & 75.46 \\
\hline
\end{tabular}

\section{Histopathological analysis}

Parameters (thickness of the epidermis, collagen fiber matrix) were evaluated during histopathological examination, in which tissue sample collected at the wound site at the end of the study in the pathology laboratory. Histopathological examination showed that the best development of epithelium and collagen fiber deposition with collagenization and neovascularization along with fibroblasts in a group that received medication of manuka honey and povidone iodide gel (Fig. 13) combination infiltration of cells also noticed in this group. The skin remain intact in combination group as compared to other treatment group (Fig. 14, 15, 16 \& 17). There is more cellular infiltration at the site of wounds that were treated along manuka honey and povidine gel. There is significant differences among other group as compared to other treatment group. 


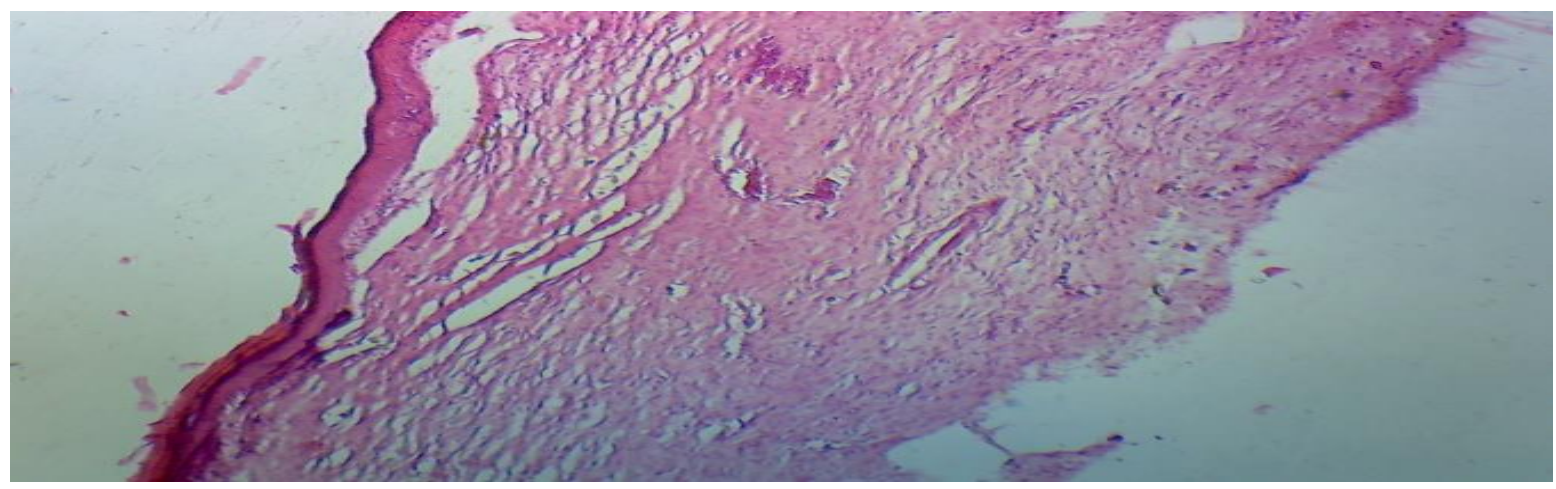

Figure 13. Healed wound treated with Manuka honev and Povidone iodide

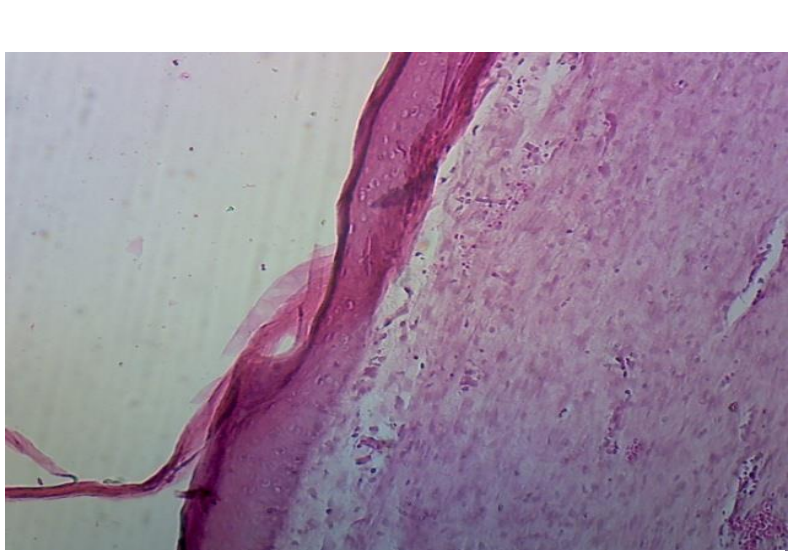

Figure 14. Histological view of healed wound treated with manuka honev

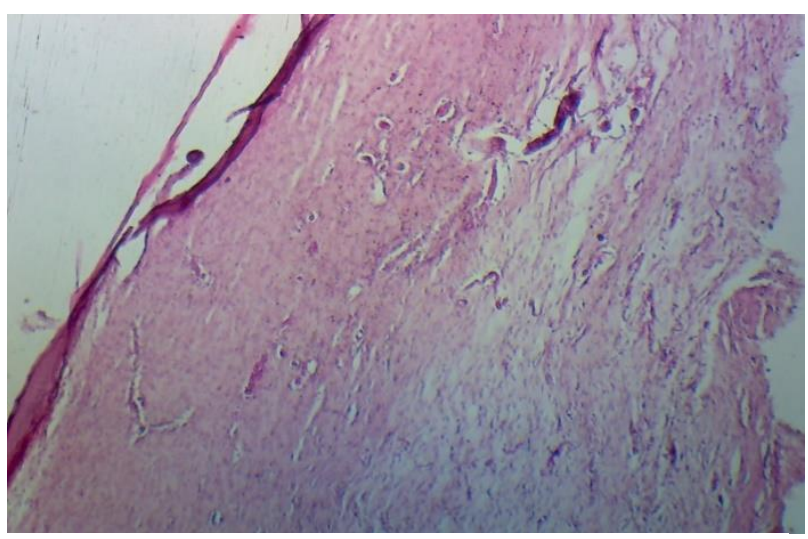

Figure 16. Histological view healed wound in group D

\section{Discussion}

The outer covering of living organism the skin, which is largest organ of living body. Skin basically consists of many layers epidermis, dermis, and subcutaneous tissue. Traumatic injuries, surgical or idiopathic various diseases causes tissue damaged. Healing of wounds is a sequential,

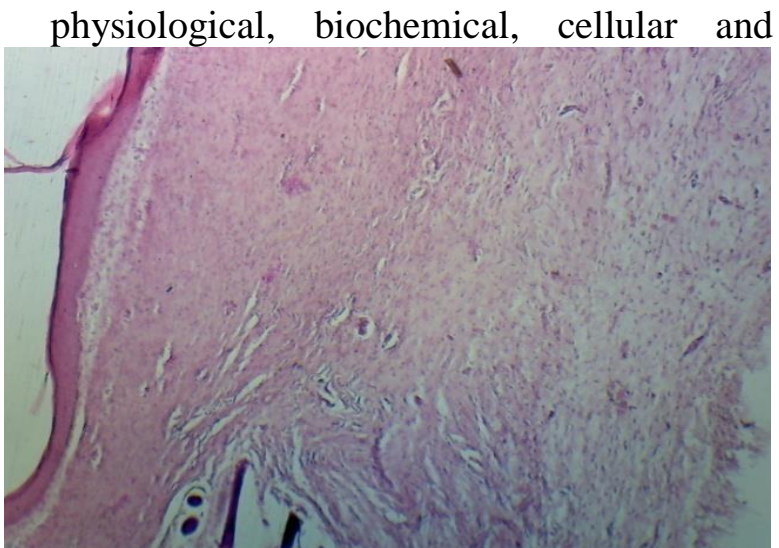

Figure 15. Histological view of healed wound treated with povidone odide gel

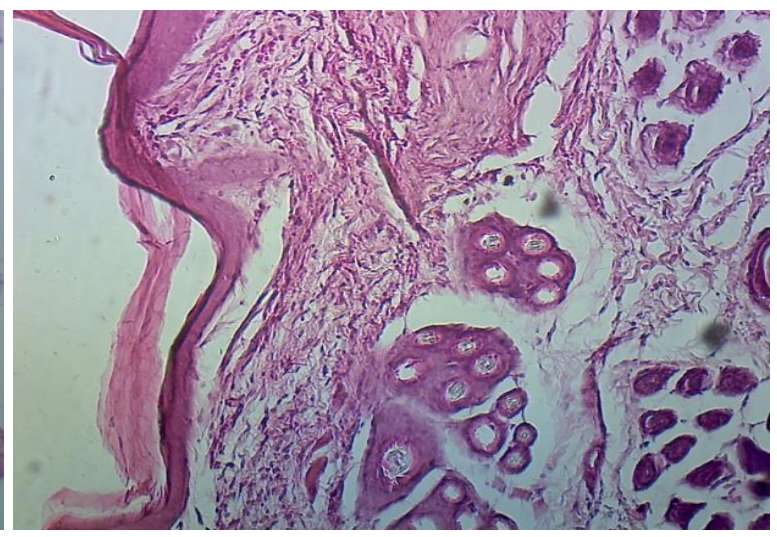

Figure 17. Healed wound treated with manuka honey

complex process that occur in living organism in response to tissue damaged. Any delay or presence of any infection at the site of wound results in unclosure of wound and delayed wound healing .Delayed closure of wound or opening of wounds still maintain importance in the field of surgery [9].

The recent research trail was deliberate and conduct to estimate the wound healing 
efficiency of Manuka honey in incisional wounds and compare to its combination with povidone iodide and povidone iodide alone. The outcomes were noted in relations of healing time, wound contraction percentage as well as histopathologic evaluation.A variety of works was conducted already on the useful properties of honey [10] comprises antibacterial property, debriding ability, deodorizing action plus osmotic pressure, antioxidant ability, anti-inflammatory property, in addition to this speed up the rate of healing of wounds.

In current study, time of healing was reduced by using combination of manuka honey and povidone iodide gel in induced incised wounds. This may be due to sugar contents found in honey, which with growth aspect mixture improved the materialization of granulation tissue, number of blood vessels, re- epithelialization as well as development of collagen matrix. The development in healing process with honey and povidone gel may also due to the antimicrobial as well as antiinflammatory activity. Honey enhances wound healing by pull down $\mathrm{pH}$ plus high free acid content which minimize the development of microbes. Certain advantageous qualities of honey is easy availability, establishment of physical obstacle against microbes. Honey provides a moist environment at the wound area as a result speed up the development of healing. The consequences of fast healing along acacia honey w be preferred by [11].

The main antimicrobial factor present in all kinds of honey is related with its hydrogen peroxide contents. In manuka honey antimicrobial and bacterialcidal activity is due to various other present in it [12]. Certain polyphenolic acidic compounds as well as flavonoids have been stated to be existing in bioactive medical grade manuka honey [13]. Manuka honey have also showed many other biological properties including the antiadehsive properties, providing very beneficial in preventing dental plaques deposits [14].

Iodine is effective topical antimicrobial that used clinically for the management of wounds for more than one hundred and seventy years. Abroad spectrum of antibacterial ability with effectiveness against bacteria, mycobacteria, fungi, protozoa plus viruses and can be used to treat both acute and chronic wounds. It is also relatively inexpensive and easy to use, but isoften underused as a local antiseptic due toits perceived toxicity.

In the present study, the treatments groups were four namely A, B, C, D. In group A rabbits were treated with topical application of manuka honey. Group B animals were cured with povidone iodode gel, group C rabbits were treated mixture of manuka honey and povidone iodide gel and group D kept as control. In my research, healing time was shortest the wounds of group $\mathrm{C}$ having a mixture of manuka honey and povidone gel treated rabbits. The lessening of healing may be anticipated to the high concentration of sugars in honey which improved the formation of granulation tissue, promoted angiogenesis, galvanized re- epithelialization and speed synthesis of collagen fibers. The reason for speediest wound healing with manuka honey and povidone iodide was also due to to antibacterial and anti- inflammatory activities of manuka honey.

The early and rapid healing in honey and combination of povidone iodide gel group might be due to honey possesses a high level of glycine, methionine and proline which play an important role and definite role in collagen fiber formation. The high concentration of sugar content in honey may also be favorable for an early formation of granulation tissue. Further, the anti-microbial property of honey was due to methylglyoxal. Honey is also excellent energy source in catabolic environment. This is one of the factors enhancing the healing process [15]. In this study we have shown that manuka honey and povidone iodide gel can be used in incisional full thickness open wounds as a treatment in rabbits. Three ingredients in honey are responsible for its wound healing capabilities. Povidone iodide is oldest and cheapest antiseptic agents used as antiseptic as well as for treatment of wounds. PI used from ancient times, it also used to clean the area from microorganism prior to surgery.

Histopathological estimation in recent study revealed that the group cured with 
combination of manuka honey and povidone iodide gel (with equal quantity of manuka honey as well as povidone iodide gel ) wounds showed best development of epidermis among all groups of treatment that is manuka honey alone treatment group, povidone iodide gel treatment group and control group. The thickness of the skin layers in group $\mathrm{c}$ (manuka honey and povidone iodide gel) from animals from other groups A and B (treated with manuka honey only and povidone iodide gel alone).

However, the presence of collagen fibers was less significantly different in group $\mathrm{C}$ from the group $\mathrm{A}$, but still highly significantly different in group $\mathrm{C}$ from group $\mathrm{B}$.

\section{Conclusion}

This research has determined that the manuka honey mixture along povidone iodide gel not just increases the wound healing by endorsing wound contraction rate, also helps in better epithelialization and tissue regeneration. So it is suggested that the practice of manuka honey in mixture with equal quantity of povidone iodide for treatment of induced incisional open wounds in human as well as in animals. This combination is effective and can be used without any fear of demerits.

\section{Authors' contributions}

Designed the research project: N Saleem \& SA Khan, Performed the experiments: N Saleem, Provides financial support: K Ishfaq \& N Saleem, Contributed materials/ analysis/ tools: M Saqib, MFEA Kulyar, M Mehmood \& A Khalid, Analysis paper writing and interpretation of data: SA Khan.

\section{References}

1. Jan WA, Shah H \& Khan M (2012). Comparison of conventional pyodine dressing with honey dressing for the treatment of diabetic foot ulcers. J Postgrad Med Inst 26.

2. HamptonS, Collins F (2004). Tissue viability. London. Whurr pp 76-131.

3. Noori S,Waili A, Salom K, Ahmad A \& Ghadmi A (2010).Honey for Wound Healing Ulcer and Burns .The Sci Wor J 11: 766-787.

4. Bowler PG (2003). The 105 bacterial growth guideline: re assessing its clinical relevance in wound healing. Ostomy Wound Manage 49: 44-53.

5. Malone M \& Tsai G (2016). Wound healing with apitherapy: a review of the effects of honey. J Apither 1: 2-9

6. Juraj M (2013). Honey an immunomodulator in wound healing. Wound Repair and Regeneration.

7. Soundara PS (2005). Ketamine Xylazineanaesthesia in rabbits. Indian Vet J 82:388-389.

8. Khan F R, Abadin Z U, Rauf N (2007). Honey:nutritional and medicinal value. Intern J Clin Pract 6: 1705-1711.

9. Barisotun \& Yucel UM (2019). Wound healing effect of different extract of Centaureia Petrocaula Bangladash. $J$ Pharmocol 14: 9-16.

10. Molan PC (1992). The antibacterial activity of honey: The nature of the antibacterial activity. Bee World 73: 528.

11. SudhakarRG V, Selvaraj J, Ramanan R S, Radhakrishnan S \& Manhor BM (2003). The Efficacy of some indigenous medicine in wound healing in rats. Ind $J$ Anim Sci 73: 652- 653.

12. Mavric E, Wittmann S, Barth G \& Henle $T$ (2008). Identification and quantification of methyl glyoxal as the dominant antibacterial constituent of Manuka (Leptospermum scoparium) honeys from New Zealand. Mol Nutr Food Res 52: 483-489.

13. Gethin G \& Cowman S (2015). Manuka honey vs. hydrogel-a prospective, open label, multicentre, randomised controlled trial to compare desloughing efficacy and healing outcomes in venous ulcers. J Clin Nurs 24: 2686.

14. Labrecque J, Bodet C, Chandad F \& Grenier D (2006). Effects of a highmolecular- weight cranberry fraction on growth, biofi;m formation and adherence of Porphyromonas gingivalis. $J$ Antimicrob Chemotherp 58: 439- 433.

15. Gupta SK, Singh H, Varshney AC \& Prakash P (1992). Therapeutic efficacy of honey in infected wounds in buffaloes. Ind J Anim Sci 62: 521-523. 